\title{
Mineral and Bone Disorder in Chronic Kidney Disease: A Case Report from Vietnam
}

\author{
Pham Van Bui ${ }^{a} \quad$ Nguyyen Minh Tuan ${ }^{b}$ Huynh Thi Nguyen Nghia ${ }^{a}$ \\ Pham Nguyen Thanh Phuong ${ }^{c}$ \\ ${ }^{a}$ Pham Ngoc Thach University of Medicine, ${ }^{b}$ Cho Ray Hospital, and ${ }^{C}$ FV Hospital, Ho Chi Minh City, Vietnam
}

\section{Keywords}

Maintenance hemodialysis - Mineral and bone disorder . $\beta 2$ microglobulin · Xanthine oxidase inhibitors . Calcium phosphate deposition disease

\begin{abstract}
We report a case of calcium pyrophosphate dihydrate deposition disease (CPDD) involving a patient on maintenance hemodialysis (MHD). The 32-year-old man presented in August 2016 with a complaint of left shoulder swelling of 8 months' duration with no trauma or fever. He was diagnosed with nephrotic syndrome in 1998, which progressed to ESRD. He commenced MHD in 2012. Examination at our hospital revealed a soft nontender swelling of the left shoulder. Blood biochemistry showed elevated serum urate, phosphate, $\beta 2$ microglobulin, and parathyroid hormone. Imaging revealed joint effusion and dense heterogenous deposition. Aspirate analysis showed urate crystals 3+, and culture yielded no growth. Following rheumatology review, the working diagnosis was periarticular tissue tuberculosis, after excluding pseudogout and amyloidosis. Following 1 month of colchicine and allopurinol, synovial fluid microscopy showed
\end{abstract}

\section{KARGER}

(C) 2017 S. Karger AG, Basel

E-Mail karger@karger.com

www.karger.com/bpu
CPDD crystals. Symptoms gradually resolved over the course of 6 months. In this rare case, a diagnosis of CPDD was made with a multidisciplinary approach that included imaging and biochemical investigations.

(c) 2017 S. Karger AG, Basel

\section{Introduction}

Mineral and bone disorder (MBD) with musculoskeletal system involvement is a common complication seen in patients with end-stage renal disease (ESRD) or those receiving long-term maintenance dialysis (MHD) usually for more than 15 years [1]. Musculoskeletal complications in patients on MHD may manifest in the joints or soft tissues, or both [1]. The clinical manifestations of joint involvement vary and may include calcium phosphate deposition disease (CPDD), gout, pseudogout, pseudorheumatoid arthritis, pseudoneuropathic ar-

See www.karger.com/doi/10.1159/000479576 for an infographic on Country Status.

Pham Van Bui

Pham Ngoc Thach University of Medicine

$86 / 2$ Thanh Thai Street, District 10

Ho Chi Minh City (Vietnam)

E-Mail bui.pham@fvhospital.com 


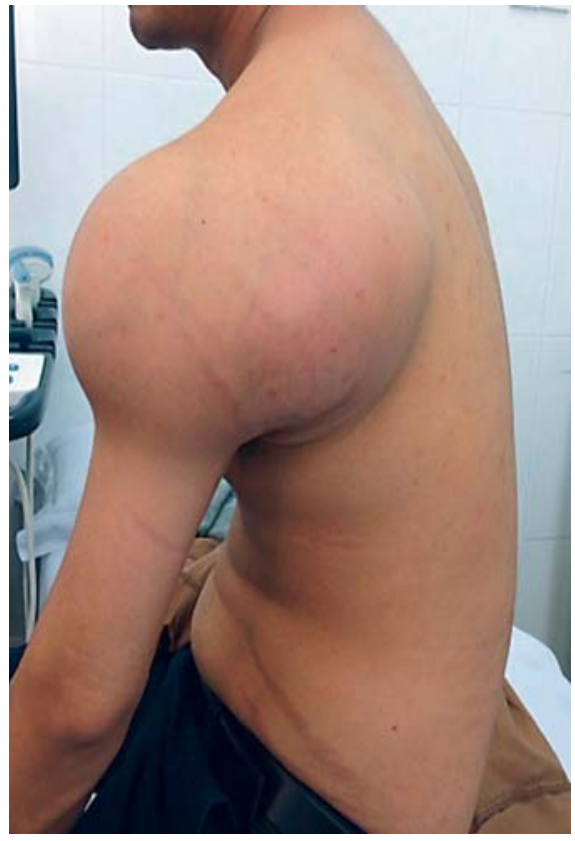

Fig. 1. A large round tumefaction over the deltoid region measuring $20 \times 30 \mathrm{~cm}$ at presentation.

thropathy, amyloidosis, osteoarthritis, carpal tunnel syndrome, septic arthritis, and various crystal-induced arthropathies [2].

Crystal-induced arthropathy is an important cause of acute joint inflammation in patients with renal failure and is most commonly caused by basic calcium phosphate crystal deposition [3]. In a study by Gutman et al., musculo-articular complications in patients on long-term hemodialysis and peritoneal dialysis, attributed to $\beta 2$ microglobulin $(\beta 2 \mathrm{M})$ amyloid deposition, have been described as a triad of shoulder periarthritis, carpal tunnel syndrome, and flexor tenosynovitis of the hands [4].

Deposition of calcium pyrophosphate dihydrate in and around the joints, especially in articular cartilage and fibrocartilage, is a metabolic arthropathy and is referred to as CPDD [5]. CPDD is the most common cause of secondary metabolic osteoarthritis, usually affecting the knees, wrists, and hips, commonly presenting as asymptomatic CPDD, acute pseudogout, pseudo-osteoarthritis, pseudorheumatoid arthritis, or pseudoneuropathic arthropathy. CPDD is associated with aging and therefore occurs mainly in the elderly $[2,5]$. It is slightly more common in women than in men; the exact female-to-male ratio is unknown but is thought to be 1.4:1 [2]. CPDD in
Table 1. Laboratory investigations on admission and at 1-month follow-up

\begin{tabular}{|c|c|c|c|}
\hline & $\begin{array}{l}\text { On } \\
\text { admission }\end{array}$ & $\begin{array}{l}\text { 1-month } \\
\text { follow-up }\end{array}$ & Normal \\
\hline $\mathrm{RBC}, \mathrm{T} / \mathrm{L}$ & 4.84 & 4.59 & $4.2-5.4$ \\
\hline $\mathrm{Hb}, \mathrm{g} / \mathrm{L}$ & 107 & 102 & $12-16$ \\
\hline WBC, G/L & 6.18 & 6.55 & $4.0-10$ \\
\hline $\mathrm{N}, \%$ & 56.2 & 57.4 & $40-60$ \\
\hline $\mathrm{L}, \%$ & 31.6 & 31.4 & $20-40$ \\
\hline PLT, G/L & - & 221 & $150-400$ \\
\hline $\mathrm{Na}, \mathrm{mmol} / \mathrm{L}$ & 131 & - & $135-145$ \\
\hline $\mathrm{K}, \mathrm{mmol} / \mathrm{L}$ & 4.3 & - & $3.5-5$ \\
\hline $\mathrm{Cl}, \mathrm{mmol} / \mathrm{L}$ & 92 & - & $98-105$ \\
\hline Calcium, mmol/L & - & 2.2 & $2.15-2.16$ \\
\hline Phosphorus, mg/L & 77.1 & 53.9 & $25-42$ \\
\hline Albumin, g/dL & 3.6 & 3.6 & $35-50$ \\
\hline $\mathrm{ALT}, \mathrm{U} / \mathrm{L}$ & 15 & 18 & $<33$ \\
\hline AST, U/L & 9 & 15 & $<32$ \\
\hline $\mathrm{BUN}, \mathrm{mg} / \mathrm{dL}$ & 80 & 58 & $3-20$ \\
\hline Creatinine, $\mathrm{mg} / \mathrm{dL}$ & 8.5 & 6.47 & $0.6-1.2$ \\
\hline Alkaline phosphatase, U/L & 77.1 & 231.2 & $53-130$ \\
\hline Uric acid, mg/dL & 12.4 & 6.7 & $2.4-7$ \\
\hline$\beta 2$ microglobulin, $\mu \mathrm{g} / \mathrm{L}$ & 34.590 & 31.550 & $780-1,600$ \\
\hline PTH, pg/mL & 104 & 137 & $21-45$ \\
\hline HBsAg & Negative & - & Negative \\
\hline Anti-HCV & Positive & - & Negative \\
\hline Anti-HIV & Negative & - & Negative \\
\hline
\end{tabular}

ALT, alanine transaminase; anti-HCV, hepatitis $\mathrm{C}$ virus antibody; anti-HIV, human immune deficiency virus antibody; HBsAg, hepatitis B surface antigen; AST, aspartate transaminase; $\mathrm{BUN}$, blood urea nitrogen; $\mathrm{Cl}$, chloride; $\mathrm{Hb}$, hemoglobin; $\mathrm{K}$, potassium; L, lymphocytes; N, neutrophils; Na, sodium; PLT, platelets; $\mathrm{PTH}$, parathyroid hormone; RBC, red blood cells; WBC, white blood cells.

patients with renal failure has seldom been reported in the literature. We describe here a rare case of CPDD in a young male patient who had been on MHD for only 4 years.

\section{Case Report}

A 32-year-old male patient who had been receiving MHD for about 4 years presented to us in August 2016 with left shoulder swelling. He was diagnosed with nephrotic syndrome at age 18 years and treated with unknown medications at a provincial hospital and later at a ministerial hospital. He withdrew from treatment himself in 2011. In 2012, he started MHD for ERSD at a provincial hospital, $3 \mathrm{~h}$ thrice weekly, using polysulfone low flux dialyzers each reused 6 times. In 2015, he was transferred to a private hospital in Ho Chi Minh City for MHD, $4 \mathrm{~h}$ thrice weekly with hemodialfiltration (HDF) online once every 2 weeks. Eight months 
Fig. 2. X-rays at presentation show a heterogeneous dense deposition in the left shoulder joint.
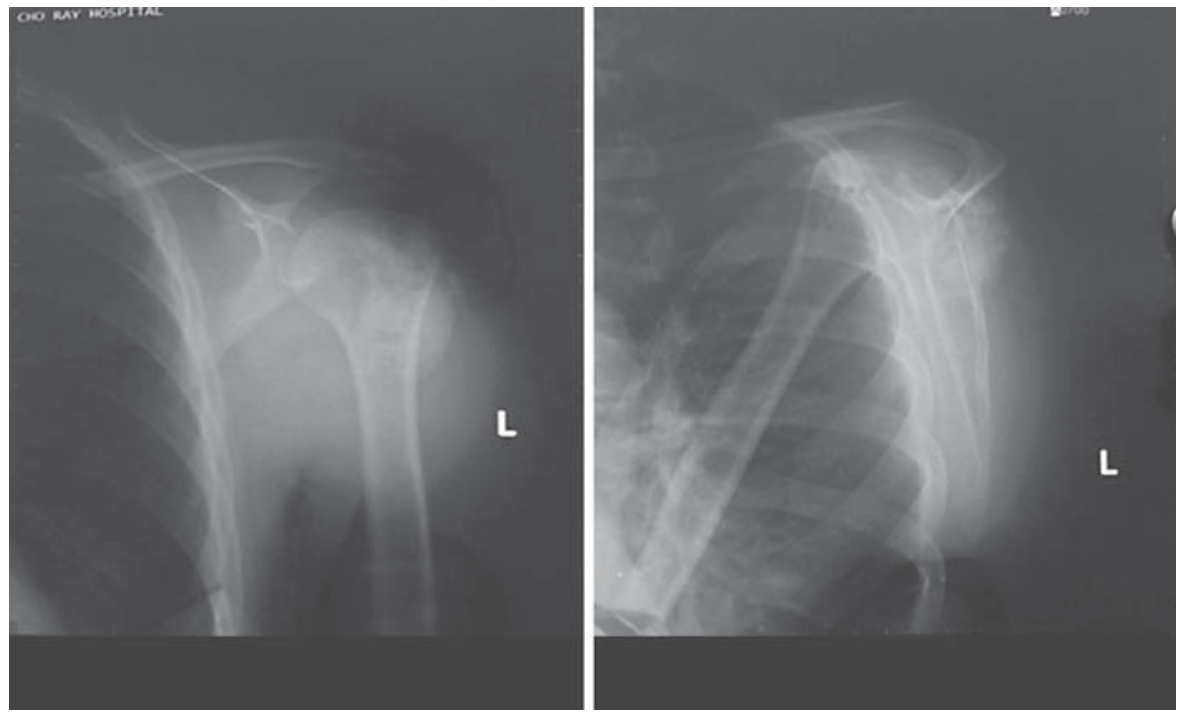

prior to presentation, his condition worsened and he developed painless swelling of the left shoulder without fever. He was referred to our ministerial hospital and admitted for further investigations in August 2016.

On examination, he was alert and cooperative with a pulse rate of $80 \mathrm{bpm}$ (regular). His blood pressure was $140 / 80 \mathrm{~mm} \mathrm{Hg}$, respiratory rate was $18 / \mathrm{min}$, and he was afebrile $\left(37^{\circ} \mathrm{C}\right)$. There was no edema. Residual urine volume was $0 \mathrm{~mL} / 24 \mathrm{~h}$. Mucosa were apparently normal. No abnormality of the heart, lungs, or abdomen was detected. The left shoulder had a round tumefaction $(20 \times 30 \mathrm{~cm})$, which was soft, nontender, immobile, borderless, and with no cutaneous fistula (Fig. 1). Initial diagnosis was amyloidosis in an MHD patient, after ruling out lipoma, synovial cyst, and osteoarthritis.

Laboratory investigations showed hematological indices were normal (Table 1). There was hyperuricemia and hyperphosphatemia of $12.4 \mathrm{mg} / \mathrm{dL}(2.4-7 \mathrm{mg} / \mathrm{dL})$ and $77.1 \mathrm{mg} / \mathrm{L}(25-42 \mathrm{mg} / \mathrm{L})$, respectively. $\beta 2 \mathrm{M}$ was elevated $34.590 \mu \mathrm{g} / \mathrm{L}(780-1600 \mu \mathrm{g} / \mathrm{L})$, as was parathyroid hormone $104 \mathrm{pg} / \mathrm{mL}(21-45 \mathrm{pg} / \mathrm{mL})$. The patient tested positive for anti-HCV but negative for HBsAg and HIV. Serum albumin, calcium, alkaline phosphatase, urea, and electrolytes were otherwise normal. Liver enzymes were also normal. Kt/V was 1.4.

Ultrasound showed cloudy subcutaneous fluid accumulation (diameter $35 \mathrm{~cm}$ ), and X-ray showed heterogeneous dense deposition in left shoulder joint (Fig. 2). A rheumatologist was consulted and the working diagnosis was suspected periarticular tissue tuberculosis, after ruling out pseudogout arthritis and amyloidosis.

Aspiration of the effusion in the biceps long head tendon sheath yielded about $5 \mathrm{~mL}$ of yellowish pus and that of the periarticular tissue yielded $400-500 \mathrm{~mL}$ of cloudy yellowish fluid. The aspirate was analyzed and direct Gram staining was negative, Mycobacterium PCR was negative, and culture yielded no growth. Urate crystals were present $(3+)$.

The patient was placed on colchicine $1 \mathrm{mg}$ QD when necessary to control the pain and allopurinol $300 \mathrm{mg}$ QD with a schedule of HD of $4 \mathrm{~h}$ thrice weekly: 1 session using a high flux dialyzer with $1.8 \mathrm{~m}^{2}$ of membrane surface area (Xevonta, B. Braun, Melsungen, Germany), 1 session of online HDF (high flux 1.8, Xevonta), and

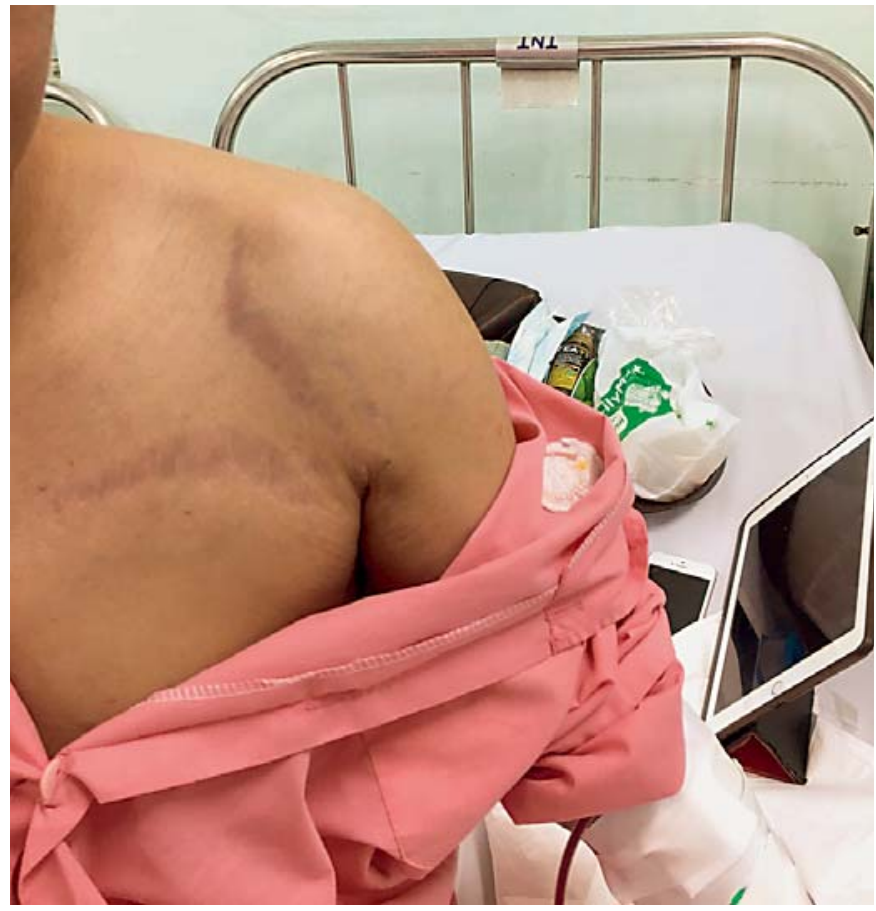

Fig. 3. At the latest follow-up around 6 months after treatment commenced, there is a marked reduction in the size of the swelling.

1 session using an adsorption membrane (HA 130, Jafron Biomedical, China).

One month after treatment, swelling of the left shoulder had reduced and the patient felt more comfortable in his daily activities. Laboratory investigations revealed improved levels of uric acid (6.7 mg/dL from $12.4 \mathrm{mg} / \mathrm{dL})$ and phosphorus $(53.9 \mathrm{mg} / \mathrm{L}$ 


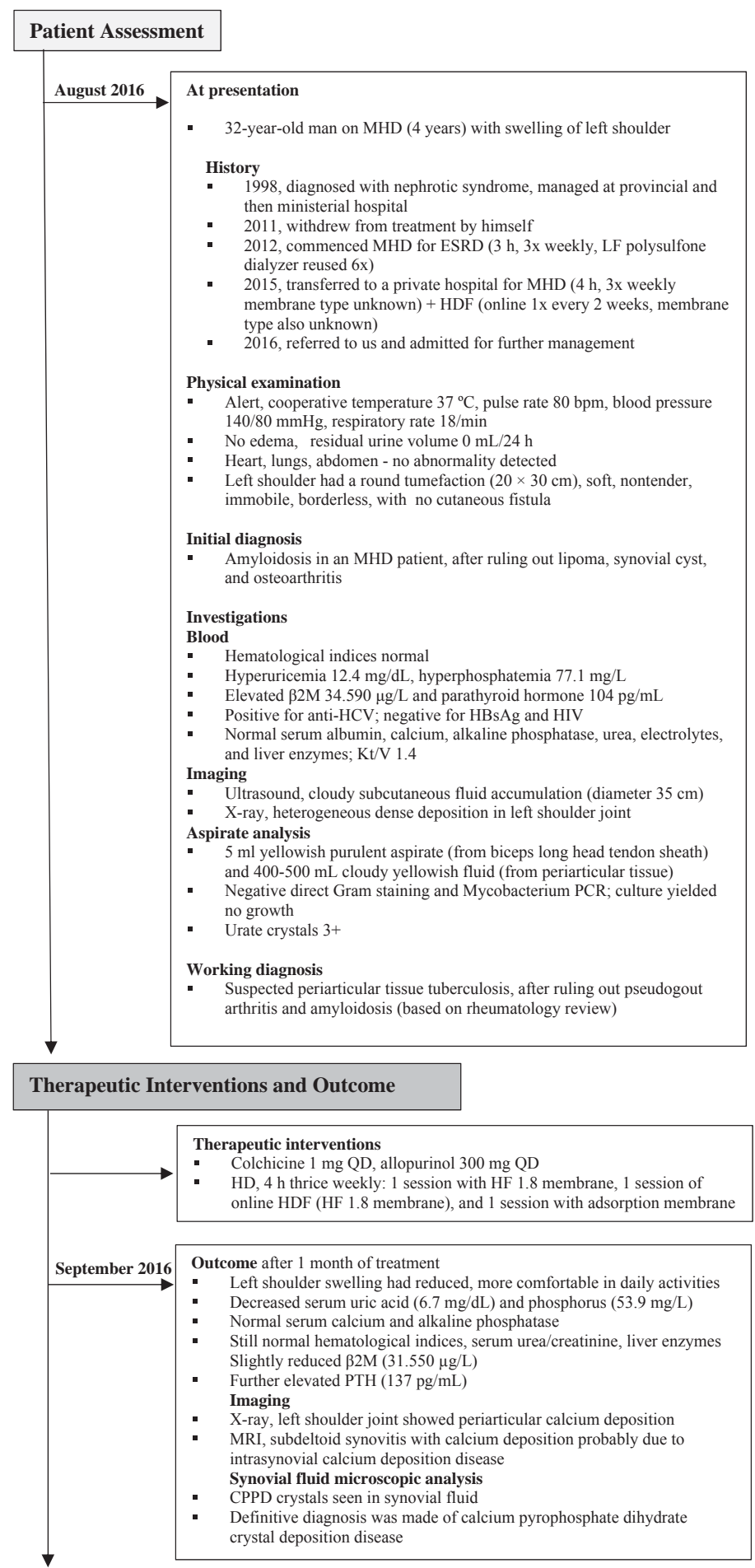

\section{Follow-up Assessment of Outcomes}

Fig. 4. Timeline of the patient's course.

$\stackrel{\text { February } 2017}{\longrightarrow} \begin{aligned} & \text { Latest follow-up visit after } 6 \text { months of treatment } \\ & \text { Final diagnosis } \\ & \text { - Calcium pyrophosphate dihydrate crystal deposition disease }\end{aligned}$

Mineral and Bone Disorder in Chronic Kidney Disease
Blood Purif 2017;44(suppl 1):46-51

DOI: $10.1159 / 000479619$ 
from $77.1 \mathrm{mg} / \mathrm{dL}$; Table 1). Serum calcium and alkaline phosphatase were normal. Hematological indices, serum urea/creatinine, and liver enzymes were still within normal reference range. $\beta 2 \mathrm{M}$ had slightly reduced to $31.550 \mu \mathrm{g} / \mathrm{L}$ (from $34.590 \mu \mathrm{g} / \mathrm{L}$ ), whereas PTH had further increased to $137 \mathrm{pg} / \mathrm{mL}$ (from $104 \mathrm{pg} / \mathrm{mL}$ ). X-ray of the left shoulder joint showed calcium deposits in the periarticular tissue. MRI revealed subdeltoid synovitis with calcium deposition probably due to intrasynovial calcium deposition disease. A diagnosis of calcium pyrophosphate dihydrate crystal deposition disease was made based on synovial fluid microscopic examination performed by a specialist pathologist.

At the most recent follow-up in February 2017, the swelling had reduced (Fig. 3); unfortunately, blood chemistry was not performed because he has since returned to his province for dialysis and the required blood tests cannot be performed there. A timeline of the patient's course is shown in Figure 4.

\section{Discussion}

To the best of our knowledge, this is the first report in Vietnam of a case of MBD in chronic kidney disease despite adequate dialysis. This case is peculiar because CPDD occurred in a young male patient who had been on MHD for only 4 years; according to the literature, this disorder usually occurs in the elderly or in patients who have been on MHD for a much longer time $[1,2,5]$.

Treatment was successful but clinical questions remain. The first concerns the question of differential diagnosis as to whether this is a case of gout, pseudogout, amyloidosis, or a combination of these conditions. There are few reports of CPDD, especially involving the shoulder joint, because the knee, wrist, and hip joints are most often affected. Pseudogout is characterized by acute monoarticular or oligoarticular arthritis usually involving the knee or wrist joint; pseudo-osteoarthritis often involves the metacarpophalangeal joints; and primary osteoarthritis does not usually affect the wrist, elbow, or shoulder joints [2]. Yildiz et al. reported CPDD with clinical manifestation resembling pseudogout in both knee and wrist joints in a uremic patient [2]. In a retrospective study of 1,070 patients over 65 years of age, the prevalence of symphysis pubis chondrocalcinosis (a radiographic feature of CPDD) revealed by consecutive computed tomographic scans of the abdomen and pelvis was $21.1 \%$; these patients were non-uremic [6]. In the present case, the diagnosis was reached by a multidisciplinary approach, including imaging and biochemical investigations.

The exact mechanism underlying the development of CPDD remains unknown, although hyperphosphatemia, hyperuricemia, and high serum levels of parathyroid hormone and $\beta 2 \mathrm{M}$ may be contributory factors. Of these, $\beta 2 \mathrm{M}$-derived amyloidosis (or dialysis-associated amyloidosis) might explain why CPDD affected our patient's shoulder joint because its clinical manifestations are mainly at osteoarticular sites, particularly synovial membranes with recurrent joint effusions and synovitis, often in the shoulders and knees [1]. Other pathogenic factors could not be investigated due to lack of sophisticated laboratories in our country, such as cartilage matrix changes, genetic defects in ANKH, COL, and TNFRSF11B genes, and increased adenosine triphosphate breakdown resulting in increased inorganic pyrophosphate in the joints from aging, genetic factors, or both [2].

The second clinical question concerns management in this patient, which comprised mainly medical treatment with intensive dialysis. Ultrapure dialysate (which is not common in Vietnam), bicarbonate buffer, and high flux hemofiltration have been proven to ameliorate the clinical features of amyloidosis, and probably other combined treatment options need to be investigated. For example, initially we had only allopurinol, but now febuxostat, a non-purine-selective xanthine oxidase inhibitor, is available and is preferable because allopurinol is commonly switched to febuxostat and most patients switching to the recommended dose will reach their target serum uric acid level. Moreover, the European League Against Rheumatism (EULAR) recommends allopurinol as first-line therapy for patients with normal renal function, and if hyperuricemia is not ameliorated with allopurinol, then febuxostat, a uricosuric agent, or a combination of a xanthine oxidase inhibitor and a uricosuric agent may be used. Febuxostat is much more expensive but extensive studies showed it was well tolerated (eGFR values as low as 15 $\mathrm{mL} / \mathrm{min} / 1.73 \mathrm{~m}^{2}$ ) and requires no dose adjustments in dialysis [7].

Arthrocentesis is the most important procedure, especially in patients with acute pseudogout or recurrent synovial effusion. Aspiration of fluid from affected joints not only helps to relieve symptoms but may also contribute to the etiological diagnosis from microscopic examination and aspirate culture, as well as guide the choice of appropriate treatment [2].

Long-term management of this patient is needed and will involve control of gout and the other comorbidities, adequate monitoring, and careful follow-up. This includes effective control of uric acid to relieve the symptoms of gout and treatment of CPDD, with monitoring of serum $\mathrm{Ca} / \mathrm{P}$ to investigate for $\mathrm{PTH}$ disorders and of $\beta 2 \mathrm{M}$ as an index of the outcomes of intensive dialysis. The synovial effusion will also be monitored to prevent recurrence.

\section{0}

Blood Purif 2017;44(suppl 1):46-51 DOI: $10.1159 / 000479619$
Bui/Tuan/Nghia/Phuong 
Our patient developed MBD despite adequate dialysis. CPDD should have been included in the initial working diagnosis because of the crystal deposition. However, it was not considered because we had no prior experience of this disorder, which typically occurs in the elderly or in patients on long-term MHD [1] and predominantly affects the knee, wrist, hip joints, and the symphysis pubis [5]; our patient is young and had been on MHD for just 4 years. Moreover, the shoulder joint was involved, which is not typically the joint affected in CPDD.

Control of phosphate is crucial in the long-term management of patients with CKD, and thus phosphate binders are beneficial $[8,9]$. There are several therapeutic options for the treatment of gout, and calcium-based phosphate binders have demonstrated significant reduction in serum uric acid levels in hemodialysis patients [9]. In our case, we used calcium carbonate and vitamin $\mathrm{D}$ in a single tablet, which is the only preparation that is available to us because we have no non-calcium-based phosphate binders. The inteleukin-1 receptor antagonist anakinra can be a potential alternative for treating CPDD, especially patients with renal insufficiency such as the present case and in whom nonsteroidal drugs are contraindicated [10].

\section{Acknowledgements}

The authors thank the patient for granting permission to report his case. The authors also thank Florence Orim, $\mathrm{MD}, \mathrm{PhD}$, and Caryn Jones of ThinkSCIENCE, Japan, for medical writing support.

\section{Statement of Ethics}

The patient provided written informed consent for his case to be published.

\section{Disclosure Statement}

Writing support, for educational purposes, was funded by $\mathrm{Ni}$ pro Corporation, Japan. Nipro Corporation had no role in the selection of presented case, the collection and analysis of the data, or in the preparation of the manuscript.

\section{References}

1 Kevine JM, Floege J, Kotteler M: Bone and Mineral Metabolism in Chronic Kidney Disease; in Floege J, Johnson RJ, Feehally J (eds): Comprehensive Clinical Nephrology, ed 4. Saunders, Elsevier 2010, pp 569-984.

2 Constantine K Saadeh: Calcium Pyrophosphate Deposition Disease. http://emedicine. medscape.com/article/330936-overview (accessed May 15, 2017).

3 Kay J, Bardin T: Osteoarticular disorders of renal origin: disease-related and iatrogenic. Baillieres Best Pract Res Clin Rheumatol 2000;14:285-305.

4 Gutman RA: Characteristics of long-term (14 years) survivors of maintenance dialysis. Nephron 1983;33:111-115.
5 Abhishek, M. Doherty: Update on calcium pyrophosphate deposition. Clin Exp Rheumatol 2016;34(suppl 98):32-38.

6 Patel T, Ryan L, Dubois M, Carrera G, Baynes K, Mannem R, Mulkerin J, Visotcky A: The prevalence of chondrocalcinosis of the symphysis pubis on CT scan and correlation with calcium pyrophosphate dihydrate crystal deposition disease. Clin Rheumatol 2016;35: 771-773.

7 Richette P, Doherty M, Pascular E, Barskov V, Becce F, Castañeda-Sanabria J, Coyfish M, Coyfish S, Jansen TL, Janssens H, Lioté F, Mallen C, Nuki G, Perez-Ruiz F, Pimentao J, Punzi L, Pywell T, So A, Tausche AK, Uhlig T, Zavada J, Zhang W, Tubach F, Bardin T: 2016 updated EULAR evidence-based recommendations for the management of gout. Ann Rheum Dis 2017;76:29-42.
8 Ritter CS, Slatopolsky E. Phosphate toxicity in CKD: The killer among us. Clin J Am Soc Nephrol 2016;11:1088-1100.

9 Garg JP, Chasan-Taber S, Blair A, et al: Effects of sevelamer and calcium-based phosphate binders on uric acid concentrations in patients undergoing hemodialysis: A randomized clinical trial. Arthritis Rheum 2005;52: 290-295.

10 Announ N, Palmer G, Guerne PA, Gabay C: Anakinra is a possible alternative in the treatment and prevention of acute attacks of pseudogout in end-stage renal failure. Joint Bone Spine 2009;76:424-426.
Mineral and Bone Disorder in Chronic Kidney Disease
Blood Purif 2017;44(suppl 1):46-51 DOI: $10.1159 / 000479619$ 